\title{
Total daily energy expenditure relative to resting energy expenditure in clinically stable patients with COPD
}

\author{
Erica M Baarends, Annemie M W J Schols, Klaas R Westerterp, Emiel F M Wouters
}

\begin{abstract}
Background - An elevated resting energy expenditure (REE) commonly occurs in patients with chronic obstructive pulmonary (COPD). The purpose of this study was to investigate the effect of an increased REE on total daily energy expenditure (TDE) in 20 patients with COPD (19 men) with mean (SD) forced expiratory volume in one second of $37(14) \%$ predicted.
\end{abstract}

Methods - TDE was measured over a two week interval using doubly labelled water. Fat-free mass (FFM) was calculated from total body water assessed by deuterium dilution. REE was measured by indirect calorimetry using a ventilated hood system.

Results - The patients (10 men) with a significantly higher REE than those with a normal REE (median difference $205 \mathrm{kcal} /$ $24 \mathrm{~h}, \mathrm{p}<0.05$ ) had a comparable TDE (hypermetabolic at rest: median 2593; range 2127-3083 kcal/24 h, normometabolic at rest: median 2629; range 2032-3179 kcal/ $24 \mathrm{~h})$. There was no difference in mean daily heart rate (HR) between the groups (hypermetabolic at rest: median 92 (range 82-98), normometabolic at rest: median 98 (range $75-116$ ) beats/min) or in the variation in the heart rate during the day. By means of multiple regression analysis it was shown that REE did not correlate significantly with TDE when FFM was taken into account.

Conclusions - This study shows that there is no significant difference in free living TDE between clinically stable patients with COPD with a normal REE and those with an increased REE. The variation in TDE in patients with COPD appears to reflect differences in energy expenditure for activities, but not differences in REE. (Thorax 1997;52:780-785)

Keywords: chronic obstructive pulmonary disease, total daily energy expenditure, resting energy expenditure.

Weight loss is a common problem in patients with chronic obstructive pulmonary disease (COPD) which comprises loss of fat mass as well as fat-free mass. ${ }^{12}$ Nutritional depletion is particularly relevant for the clinical condition of patients with COPD because it adversely affects functional performance and survival. ${ }^{3-6}$

Weight loss occurs when energy expenditure exceeds energy intake - that is, when an in- dividual is in a negative energy balance. In many patients with COPD an increased resting energy expenditure (REE) has been demonstrated. ${ }^{7-9}$ REE is the energy needed for the ongoing processes in the body in the resting state when no food is digested and no energy is needed for temperature regulation. In sedentary subjects REE represents the main part of the total daily energy expenditure (TDE). The remaining components of TDE are dietinduced thermogenesis (DIT) and energy expenditure for activities, which is the most variable component.

Data concerning TDE in COPD are very limited. It is, however, difficult to obtain a reliable measurement of TDE. At the moment this is only possible by means of a respiratory chamber, or by using the doubly labelled water method. The disadvantage of the respiratory chamber is that physical activity is limited. To obtain an accurate measure of TDE, including the energy expenditure of usual daily activities, it should be measured in free living conditions which is only possible by the doubly labelled water method. We have previously reported that TDE (measured by this method) is increased in patients with COPD compared with healthy subjects matched for sex, age, and body composition. ${ }^{10}$ Since mean REE was comparable between the two groups, conclusions concerning the effect of an increased REE on TDE could not be made in this study.

Hugli et $a l^{11}$ recently measured TDE in patients with COPD and healthy subjects in a respiratory chamber. Although REE was increased in the patients with COPD, TDE was comparable between the groups. In studies of TDE in other patient groups (cystic fibrosis, human immunodeficiency virus infection (HIV)) it was found that the disease-related increase in REE was not reflected in an increased TDE compared with healthy subjects or reference values of TDE. ${ }^{1213}$ To our knowledge, a possible discrepancy in TDE between patients with a normal REE and those with a disease-related increased REE has not previously been investigated.

The aim of the present study was to investigate whether an increased REE in clinically stable patients with COPD is directly related to an increased TDE (in free living conditions).

\section{Methods}

PATIENTS

Twenty patients (19 men) with moderate to severe COPD in a stable clinical condition were
11 April 1997

Accepted for publication

30 May 1997 
Table 1 Patient characteristics

\begin{tabular}{|c|c|c|c|}
\hline & $\begin{array}{l}\text { Increased } R E E^{1} \\
\text { (group } A, n=10 \text { ) }\end{array}$ & $\begin{array}{l}\text { Normal REE } \\
(\text { group } B, n=10)\end{array}$ & $p$ value \\
\hline Age (years) & $65(57-74)$ & $69(55-78)$ & NS \\
\hline $\mathrm{BMI}\left(\mathrm{kg} / \mathrm{m}^{2}\right)$ & $23.9(16.6-32.4)$ & $24.4(17.4-28.9)$ & NS \\
\hline FFM (kg) & $46.4(41.1-60.8)$ & $48.1(40.3-58.9)$ & NS \\
\hline $\mathrm{FEV}_{1}$ (\%pred) & $38(20-72)$ & $31(21-53)$ & NS \\
\hline FVC (\%pred) & $86(65-129)$ & $88(64-105)$ & NS \\
\hline TLC (\%pred) & $118(86-132)$ & $134(92-166)$ & NS \\
\hline ITGV (\%pred) & $157(94-193)$ & $187(125-256)$ & NS \\
\hline TLCO (\%pred) & $64(52-91)$ & $60(29-106)$ & NS \\
\hline $\mathrm{PaO}_{2}(\mathrm{kPa})$ & $10.0(8.5-12.2)$ & $10.2(8.4-11.3)$ & NS \\
\hline$\beta_{2}$ agonists $(\mu \mathrm{g} / \text { day })^{2}$ & $1600(800-2000)$ & $1600(800-2000)$ & NS \\
\hline Theophyllines (mg/day) $)^{3}$ & $700(500-900)$ & $600(375-900)$ & NS \\
\hline
\end{tabular}

Data are presented as median (range).

$\mathrm{BMI}=$ body mass index $\left(\right.$ weight $/$ height $\left.^{2}\right) ; \mathrm{FFM}=$ fat-free mass $; \mathrm{FEV}_{1}=$ forced expiratory volume in one second; FVC = forced vital capacity; TLC = total lung capacity; ITGV = intrathoracic gas volume; TLCO = carbon monoxide transfer factor; $\mathrm{PaO}_{2}=$ arterial oxygen pressure.

${ }^{1}$ Increased or normal REE for FFM (fig 1).

${ }^{2}$ Cumulative daily dose; only patients using $\beta_{2}$ agonists $(n=19)$ were included in the analysis; Cumulative daily dose; only patients using $\beta_{2}$ agonists $(n=19)$ were included in the analysis;
three patients were excluded because they had an incomparable dosage due to the use of a nebuliser; group A: $\mathrm{n}=6$.

nebuliser; group A: $n=6$.
${ }^{3}$ Only patients using theophyllines $(n=16)$ were included ( $n=8$ in each group).

studied. The diagnosis was made following the criteria of the American Thoracic Society ${ }^{14}$ (table 1). Lung function measurements included flow volumes (forced vital capacity (FVC), forced expiratory volume in one second $\left(\mathrm{FEV}_{1}\right)$ ) and static lung volumes (total lung capacity (TLC), and intrathoracic gas volume (ITGV)). Carbon monoxide transfer factor (TLCO) was measured by the single breath method (Masterlab, Jaeger, Wurzburg, Germany). The highest value of at least three measurements was used and expressed as a percentage of the reference value. ${ }^{15}$ Blood was drawn from the brachial artery at rest while breathing room air. Blood gases were analysed on a blood gas analyser (Radiometer, ABL 330, Copenhagen, Denmark). Data on eight of the 19 male patients have been reported previously. ${ }^{10}$ The patients were admitted to a pulmonary rehabilitation centre for a period of 8-10 weeks but were allowed to go home at weekends. Patients with an arterial oxygen pressure of $<7.3 \mathrm{kPa}$ or those suffering from cancer, an unstable cardiac condition such as decompensated cor pulmonale, active gastrointestinal abnormalities, recent surgery, severe endocrine disorders, or locomotor diseases were excluded.

The patients were fully informed about the nature and purpose of the study and gave informed consent. The study was approved by the local ethical committee. Procedures followed were in accordance with the Helsinki Declaration of 1977 as revised in 1983.

RESTING ENERGY EXPENDITURE (REE)

REE was measured at least twice (before and during the doubly labelled water method) by open circuit indirect calorimetry using a ventilated hood system (Oxycon Beta, Jaeger, Würzburg). ${ }^{16} \mathrm{~A}$ transparent plexiglas hood was placed over the patient's head and room air was drawn through the hood at a fixed flow rate $(40 \mathrm{l} / \mathrm{min})$. The expired air of the patient mixes with the room air in the hood from which samples are taken. Oxygen consumption and carbon dioxide production were calculated from the airflow and the difference in the concentration of oxygen and carbon dioxide be- tween the incoming and outgoing air. Energy expenditure was calculated using the abbreviated Weir formula. ${ }^{17}$ Measurements were performed in the early morning after an overnight fast while the subject was lying on a bed in the supine position. The system was calibrated before measurements were taken and the accuracy of the system (3-4\%) was regularly tested with an ethanol combustion test. REE was expressed in absolute values or as percentage of predicted. ${ }^{18}$

\section{DIETARY INTAKE}

During the entire 14 days of the doubly labelled water measurement period dietary intake was obtained by means of dietary records. The dietary records were preprinted and only the amount of food components had to be completed by the patients. During weekdays the portion sizes of the (hot) meal components were weighed by the kitchen staff. During the weekends the patients were encouraged to describe the amount they ate in as much detail as possible. The dietary records were analysed by an experienced dietician and the nutrient data base was derived from the Dutch food composition tables. ${ }^{19}$

\section{TOTAL DAILY ENERGY EXPENDITURE}

The premise of the doubly labelled water technique is that after a loading of water labelled with deuterium $\left({ }^{2} \mathrm{H}\right)$ and oxygen ${ }^{18}\left({ }^{18} \mathrm{O}\right)$ the ${ }^{2} \mathrm{H}$ is eliminated from the body as water whereas the ${ }^{18} \mathrm{O}$ is eliminated from the body as water and carbon dioxide $\left(\mathrm{CO}_{2}\right)$. The difference between the elimination rates is therefore proportional to $\mathrm{CO}_{2}$ production and hence total energy expenditure. $^{20}$

Total daily energy expenditure (TDE) was determined following the standard Maastricht protocol as described by Westerterp et al. ${ }^{21}$ Late in the evening a baseline urine sample was collected. A weighted isotope dose was then administered at 22.00 hours consisting of a mixture of 10 atom percentage excess (APE) ${ }^{18} \mathrm{O}$ and $5 \mathrm{APE}{ }^{2} \mathrm{H}$. Subsequently, the isotopes equilibrate with the body water (during equilibration the patient does not consume any food or drink) and the initial urine sample was collected the next morning (day 1) from the second voiding. Further urine samples were collected in the evening of day 1 and in the morning and evening of days 8 and 15. Isotope ratios in urine samples were measured by isotope ratio mass spectroscopy (Aqua SIRA, VGIsogas, UK). Calculated carbon dioxide production was converted to energy expenditure assuming a RQ of $0.85 .^{20}$

\section{PHYSICAL ACTIVITY}

The patients participated in a pulmonary rehabilitation programme that included a standard activity programme on weekdays. The patients performed physical activities such as gymnastics, cycling and walking, strength training and/or upper extremity training. Other components of the programme included sed- 
entary activities such as educational lectures, relaxation sessions, and talks with the physician or other caretakers. In the evening no physical activities were scheduled and most patients performed sedentary leisure activities (reading, puzzles, playing games, etc.).

The energy expenditure for activities was calculated by $(0.9 \times \mathrm{TDE})-\mathrm{REE}$, assuming a DIT of $10 \%$ of TDE. Quantification of the activity level was obtained by monitoring the heart rate (HR) for 48 hours (two weekdays) using a sport tester device (PE 3000 Polar Electro, Finland). This device consists of a transmitter, a battery operated electrocardiographic monitor and a receiver, and an electronic watch with an antenna housing capable of receiving signals from the transmitter. The transmitter was strapped to the patient's anterior chest wall with a rubber belt and bandages. The receiver can store mean heart rate readings of every minute for 16 hours; thereafter the receiver was replaced by another to store the remaining eight hours of a 24 hour interval.

From these recordings several variables were obtained. Rest-HR was the mean heart rate during sleeping/resting. The heart rate during the remaining time was defined as day-HR. The standard deviation from the day-HR illustrates the variation in the heart rate during the day: VAR-HR. Furthermore, the minutes spent when heart rate was 15 beats above the day$\mathrm{HR}$ was summarised (TIME- $\mathrm{HR}^{+15}$ ), and the mean heart rate during that time was computed $\left(\mathrm{HR}^{+15}\right)$. Finally, the total number of minutes spent above twice the standard deviation of day-HR was calculated (TIME $\left.{ }^{2 \mathrm{SD}}\right)$, as well as the mean $\mathrm{HR}$ during that time $\left(\mathrm{HR}^{2 \mathrm{SD}}\right)$.

BODY COMPOSITION

Body height was measured with the subject standing bare foot and was determined to the nearest $0.5 \mathrm{~cm}$ using a stadiometer with head traction and correct posturing (Lameris WM 715, Breukelen). Body weight was measured with a calibrated beam scale with subjects bare footed and in light clothing and was determined to the nearest $0.1 \mathrm{~kg}$ (SECA, Germany). Body mass index (BMI) was calculated as weight $(\mathrm{kg})$ divided by height ${ }^{2}(\mathrm{~m})$. Total body water (TBW) was determined by deuterium dilution obtained on the first day of the doubly labelled water measurement period, and was calculated as the measured deuterium space divided by $1.04 .^{22}$ Fat-free mass (FFM) was calculated assuming a hydration factor of $73 \%$ of TBW.

ANALYSIS OF DATA

There is a significant relationship between both TDE and REE with $\mathrm{FFM}^{23}$ because the main part of FFM represents the metabolic active tissue mass which is responsible for energy expenditure. At the moment there is no generally accepted equation to predict REE based on FFM. The Harris and Benedict equations predict REE based on weight (and height, age, and sex). Considering that, in patients with COPD, depletion of FFM can occur with both
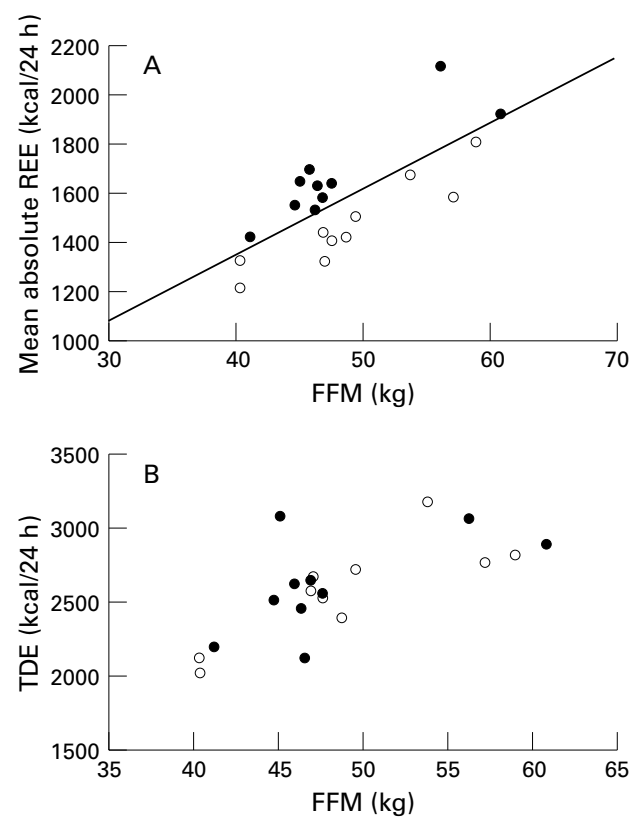

Figure 1 (A) Resting energy expenditure related to fatfree mass and (B) total daily energy expenditure related to fat-free mass; $=$ hypermetabolic at rest (group $A$ ), $\mathrm{O}=$ normometabolic at rest (group $B)$.

a decreased and a normal body weight, it is more accurate to define patients with COPD either as hypermetabolic at rest or normometabolic at rest based on metabolically active tissue mass (FFM). In order to define patients with an increased REE (group A) or a normal REE (group B), the linear regression equation between REE and FFM (measured by deuterium dilution) was therefore used in the 20 patients studied (fig 1). Patients with a REE above or below the regression equation as presented in fig 1 were assigned to group $\mathrm{A}$ and group $\mathrm{B}$, respectively.

The results are presented as median (range). The Mann-Whitney U test was used to compare values between the groups. Correlation coefficients and multiple regression analysis were used to test the linear relationship between variables. The level of significance was $5 \%$, and the Bonferroni correction was used when appropriate.

\section{Results}

As shown in fig 1A, REE correlated significantly with FFM $(r=0.73, \mathrm{p}<0.001) ; 10$ patients were assigned to group A and 10 to group B. There was no significant difference in age, body composition, lung function, or use of medication that might influence energy expenditure $\left(\beta_{2}\right.$ agonists and theophyllines) between groups $A$ and $\mathrm{B}$ (table 1).

As shown in fig $1 \mathrm{~B}, \mathrm{TDE}$ also correlated significantly with FFM $(r=0.70, \mathrm{p}<0.01)$. In fig 2 the residuals of fig $1 \mathrm{~B}$ are plotted against the residuals of fig $1 \mathrm{~A}$ and show that, when the influence of FFM is taken into account, TDE was not related to REE in these patients with COPD. Furthermore, multiple regression analysis showed that both REE $(p=0.20)$ and 


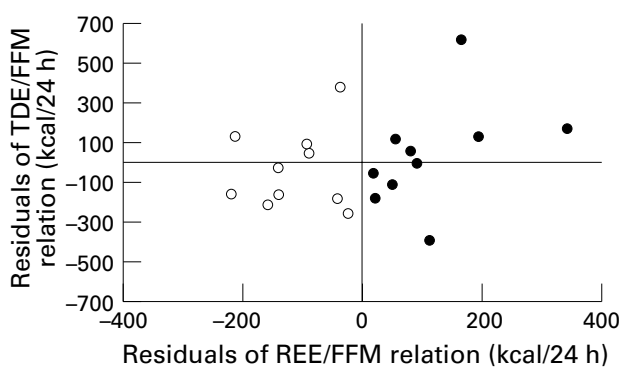

Figure 2 Total daily energy expenditure related to resting energy expenditure taking into account the relation with FFM in groups $A$ (O) and $B(\bigcirc) . y$ axis = residuals of fig $1 \mathrm{~B}, x$ axis $=$ residuals of fig $1 \mathrm{~A}$.

FFM ( $p=0.08)$ did not independently contribute significantly to the variation in TDE.

As shown in table 2, TDE did not differ significantly between groups A and B. Dietary intake was also not significantly different, although the percentage intake of carbohydrate in group A was increased compared with group B (median difference $2 \%, \mathrm{p}<0.017$ ). It can be seen from table 2 that dietary intake was lower than TDE. However, the patients were in energy balance at the time of the study since weight remained stable from the first day of the doubly labelled water method (mean 63.9 (range 49.1-92.5) kg) until the last (63.9 (50.291.7) $\mathrm{kg}$ ) in both groups, suggesting that food intake was not fully reported. The estimated energy expenditure for activities $(0.9 \times$ TDE - REE) tended to be higher in group $B$ than

Table 2 Energy expenditure and dietary intake

\begin{tabular}{|c|c|c|c|}
\hline & $\begin{array}{l}\text { Increased } R E E^{1} \\
\text { (group } A, n=10 \text { ) }\end{array}$ & $\begin{array}{l}\text { Normal REE } \\
\text { (group } B, n=10 \text { ) }\end{array}$ & $p$ value \\
\hline \multicolumn{4}{|l|}{ Resting energy expenditure } \\
\hline$(\mathrm{kcal} / 24 \mathrm{~h})$ & $1631(1423-2112)$ & $1426(1212-1802)$ & $<0.05$ \\
\hline$(\% \mathrm{H} \& \mathrm{~B})^{2}$ & $125(104-135)$ & $107(90-113)$ & $<0.01$ \\
\hline \multicolumn{4}{|l|}{ Total daily energy expenditure } \\
\hline$(\mathrm{kcal} / 24 \mathrm{~h})$ & $2593(2127-3083)$ & $2629(2032-3179)$ & NS \\
\hline \multicolumn{4}{|l|}{ Energy expended for activities } \\
\hline $0.9 \times \mathrm{TDE}-\mathrm{REE}(\mathrm{kcal} / 24 \mathrm{~h})^{3}$ & $680(288-1129)$ & $882(503-1190)$ & 0.028 \\
\hline \multicolumn{4}{|l|}{ Mean daily dietary intake ${ }^{4}$} \\
\hline Caloric intake $(\mathrm{kcal} / 24 \mathrm{~h})$ & $2070(1761-2602)$ & $2123(1604-2423)$ & NS \\
\hline$\%$ proteins & $16(14-21)$ & $16(14-20)$ & NS \\
\hline$\%$ carbohydrate & $46(40-50)$ & $44(38-45)$ & $<0.017$ \\
\hline$\%$ fat & $38(32-45)$ & $40(34-47)$ & NS \\
\hline
\end{tabular}

Data are presented as median (range).

${ }^{1}$ Increased or normal REE for FFM (fig 1).

${ }^{2}$ REE as percentage of predicted REE based on the equations of Harris and Benedict. ${ }^{18}$

${ }^{3} \mathrm{TDE}$ and REE represent independent measurements, but statistical analysis using both these two variables should be tested with $\mathrm{p}<0.05$ divided by 2 (Bonferroni correction).

${ }^{4}$ Mean daily caloric intake of the 14 days of the doubly labelled water measurement period;
Mean percentage proteins, carbohydrate and fat are dependent on each other; these variables should be tested with $\mathrm{p}<0.05$ divided by 3 (Bonferroni correction)

Table 3 Indices of activity level

\begin{tabular}{|c|c|c|c|}
\hline & $\begin{array}{l}\text { Increased } R E E^{1} \\
\text { (group } A, n=9 \text { ) }\end{array}$ & $\begin{array}{l}\text { Normal REE } \\
\text { (group } B, n=8 \text { ) }\end{array}$ & $p$ value \\
\hline Rest-HR $(x / \min )$ & $82(59-103)$ & $75(65-76)$ & NS \\
\hline Day-HR $(x / \mathrm{min})$ & $98(75-116)$ & $92(82-98)$ & NS \\
\hline $\mathrm{HR}^{+15}(x / \mathrm{min})$ & $104(83-126)$ & $100(89-102)$ & NS \\
\hline TIME-HR ${ }^{+15}(\mathrm{~min})$ & $566(254-825)$ & $627(338-872)$ & NS \\
\hline $\mathrm{HR}^{2 \mathrm{SD}}(x / \mathrm{min})$ & $125(101-143)$ & $117(106-149)$ & NS \\
\hline $\mathrm{TIME}^{2 \mathrm{SD}}$ & $33(15-69)$ & $34(10-46)$ & NS \\
\hline VAR-HR & $9.5(7.8-12.3)$ & $10.0(8.7-15.8)$ & NS \\
\hline
\end{tabular}

Data are presented as median (range)

Rest-HR = mean heart rate during sleeping/resting; Day-HR=heart rate during the remaining time; VAR-HR = standard deviation from the day-HR; TIME-HR ${ }^{+15}=$ total number of minutes spent when heart rate was 15 beats above the day-HR, and the mean HR during that time $\left(\mathrm{HR}^{+15}\right)$; $\mathrm{TIME}^{2 \mathrm{SD}}=$ total number of minutes spent at more than twice the standard deviation of day-HR, and the mean $\mathrm{HR}$ during that time $\left(\mathrm{HR}^{2 \mathrm{SD}}\right)$.

Increased or normal REE for FFM (fig 1) in group A (median difference $202 \mathrm{kcal} /$ day, $\mathrm{p}=0.028$ ). There was no correlation between pulmonary function (airflow obstruction, diffusion capacity, arterial oxygen pressure), age, body composition, or respiratory muscle strength and energy expenditure for activities. TDE divided by REE was significantly higher in the patients with a normal REE (median difference $22 \%, \mathrm{p}<0.025)$.

Seventeen patients agreed to wear the heart rate recording device for two days. Table 3 summarises the indices of activity level for group A (nine men) and group B (eight men). There was no significant difference in the day-HR, the VAR-HR, $\mathrm{HR}^{+15}$, TIME- $\mathrm{HR}^{+15}$, $\mathrm{TIME}^{2 \mathrm{SD}}$, or $\mathrm{HR}^{2 \mathrm{SD}}$ between patients in groups $\mathrm{A}$ and $\mathrm{B}$. There was no significant correlation between the energy expenditure for activities and any of these indices of heart rate monitoring.

\section{Discussion}

This study shows that there is no significant difference in free-living TDE between clinically stable patients with COPD with a raised REE (group A) and those with a normal REE (group B). Moreover, when FFM was taken into account, TDE was not related to REE. In addition, normometabolic patients at rest tended to have a higher energy expenditure for activities $(0.9 \times \mathrm{TDE}-\mathrm{REE})$ than those patients with COPD who were hypermetabolic at rest.

The ratio of TDE to REE was significantly higher in patients in group B (1.78) than in group A (1.58). Traditionally, the rate of physical activity is obtained from the ratio of TDE to REE, according to the current recommendations for energy requirements by the Food and Agriculture Organization/World Health Organization/United Nations University. ${ }^{24}$ In a recent review it was pointed out that the ratio of TDE to REE should be interpreted with care; there is a wide variation in the relationship between TDE and REE in different studies, and the regression equation of TDE with REE has shown significant intercepts in several studies. ${ }^{25}$ If the intercept of this relationship is not zero, and is different between studies, this means that the TDE to REE ratio may represent an artefact. It is therefore more accurate to examine the regression equation between TDE and REE. However, TDE and REE are both also related to FFM. Thus, in the present study it was shown that TDE was not related to REE when FFM was taken into account. As a result, TDE was similar in groups $A$ and $B$. An estimate of the absolute cost of physical activity can be obtained by subtracting REE from TDE in each individual, adjusting for the DIT. An increased DIT in patients with COPD has been reported once, ${ }^{26}$ but the most recent studies suggest a normal DIT in patients with $\mathrm{COPD}^{27}{ }^{28}$ which is approximately $10 \%$ of TDE. Combined with the comparable dietary intake by patients in groups A and B, it appears that the patients in the two groups had a comparable DIT. As TDE was comparable and REE was higher in group A than in group $B$, this resulted in a tendency for an increased 
energy expenditure for activities in the patients with a normal REE.

The question remains whether this is a consequence of a difference in physical activity level or a difference in energy expenditure for a given activity. By monitoring the heart rate it was found that there was no significant difference between the resting heart rate, daily heart rate, or variation in heart rate between the groups of patients with a different REE. We used heart rate monitoring as an indication of activity level because, as shown in the study by Meijer et $a l,{ }^{29}$ the daytime pattern of heart rate runs almost parallel to the pattern of body acceleration. This suggests that the level of activity was similar in both groups of patients although these data should be interpreted with care because of the small number of patients in the study. It should also be remembered, however, that all patients were encouraged to participate actively in a standardised pulmonary rehabilitation programme. We recognise that, although the doubly labelled water method measures TDE reliably, the estimate of energy expenditure of activities is indirectly calculated from the measurement of TDE and REE. The estimate of activity level by heart rate monitoring is also an indirect method. The energy expenditure for a given activity in patients with COPD should therefore be measured directly in futher investigations in order to investigate whether there is a discrepancy in the energy expenditure for a given activity in patients with COPD and either an increased or normal REE.

TDE was significantly correlated with FFM, but the slope (38.2) of the regression equation of TDE versus FFM was high in our patients compared with healthy subjects (maximum slope 33.3). ${ }^{23}$ This study therefore confirms our earlier observation ${ }^{10}$ that TDE seems to be increased in patients with COPD compared with healthy subjects. Moreover, there was no difference in TDE (or TDE adjusted for FFM) between the eight patients studied previously ${ }^{10}$ and the 12 other patients in this study (data not shown). Furthermore, it was striking that FFM and REE did not significantly contribute to the variation in TDE when they were both included in a multiple regression analysis.

It appears that the underlying mechanisms for an increased REE are not involved in stimulating TDE. An increased REE in patients with COPD has been ascribed to three factors: the influence of (chronic) inflammation, the influence of medication, and the oxygen cost of breathing. Evidence for the relationship between inflammation and REE has recently been found since, in a subset of patients with COPD who were hypermetabolic at rest, enhanced levels of inflammatory mediators were found. ${ }^{30}$ Obviously, if chronic inflammation is the major contributor to the increased REE in patients with COPD, this does not automatically increase TDE. However, the chronic inflammation probably interferes with the relationship between REE and FFM, which might explain the disturbing effect of REE on the relationship between TDE and FFM as found in the present study.
Furthermore, recent studies suggest a possible stimulating effect of, in particular, $\beta_{2}$ agonists and theophyllines on REE and TDE in patients with COPD. ${ }^{113132}$ There was no difference between the groups in the intake of either of these medications, so it is unlikely that this caused the difference in REE or energy expenditure for activities between the patient groups.

The effect of oxygen cost of breathing (OCB) on REE is probably not large since, in a study by Sridhar et $a l,{ }^{33}$ there was no correlation between OCB and REE in patients with COPD. This does not exclude the possibility that OCB may have been related to the increased TDE found in the present study, as well as our previous study. ${ }^{10}$ Studies by $\mathrm{O}^{\prime}$ Donnell and $\mathrm{Webb}^{34}$ and Belman et $a \mathrm{l}^{35}$ have demonstrated the importance of dynamic hyperinflation in COPD. It was shown that acute on chronic hyperinflation can occur during exercise in patients with COPD. ${ }^{345}$ Dynamic as well as chronic hyperinflation are important determinants of an increased intrinsic work of breathing, ${ }^{34}$ and therefore the energy expenditure of breathing. The patients in both groups suffered from chronic hyperinflation, suggesting that this might have influenced TDE irrespective of their REE. Further studies are indicated to investigate whether a possible increased energy expenditure for breathing during activities (possibly related to dynamic hyperinflation) substantially increases energy expenditure of activities.

The results of this study, as well as of our previous study, ${ }^{10}$ suggest that TDE is increased in clinically stable patients with COPD, but that the causes are probably not directly related to the suggested mechanisms for an increased REE in patients with COPD. The cause for an increased energy expenditure for activities (TDE) in patients with COPD is as yet unknown, but the present study warrants further investigation of the energy expenditure for (standardised) activities.

This study was supported by a grant from the Dutch Asthma Foundation (project number: 91.38). The authors thank Mrs CAPM Weling-Scheepers, Mrs GHM Hoebergen, Mrs API Hendriks and the kitchen staff for their assistance with the dietary records, and $\mathrm{Mr}$ A Kester for statistical advice.

1 Muers MF, Green JH. Weight loss in chronic obstructive pulmonary disease. Eur Respir f 1993;6:729-34.

2 Schols AMWJ, Wouters EFM. Prevalence and pathophysiology of nutritional depletion in chronic obstructive pulmonary disease. Respir Med 1993;87(Suppl B):45-7.

3 Wilson DO, Rogers RM, Wright E, Anthonisen NR. Bod weight in chronic obstructive pulmonary disease. Am Rev Respir Dis 1989;139:1435-8.

4 Vandenbergh E, Van de Woestijne K, Gyselen A. Weigh changes in the terminal stages of chronic obstructive lun disease. Am Rev Respir Dis 1967;95:556-66.

5 Schols AMWJ, Mostert R, Soeters PB, Greve LH, Wouter EFM. Nutritional state and exercise performance in patients with chronic obstructive lung disease. Thorax 1989;44:937-41.

6 Gray-Donald K, Gibbons L, Shapiro SH, Martin JG. Effect of nutritional state on exercise performance in patients of nutritional state on exercise performance in patients Dis $1989 ; \mathbf{1 4 0 : 1 5 4 4 - 8 .}$

7 Goldstein S, Askanazi J, Weissman C, Thomashow B, Kinney JM. Energy expenditure in patients with chronic obstructive pulmonary disease. Chest 1987;91:222-4.

8 Schols AMWJ, Fredrix EWHM, Soeters PB, Westerterp $\mathrm{KR}$, Wouters EFM. Resting energy expenditure in patients with chronic obstructive pulmonary disease. Am $\mathcal{F}$ Clin Nutr 1991;54:983-7.

9 Schols AMWJ, Soeters PB, Saris WHM, Wouters EFM. Energy balance in patients with chronic obstructive pulmonary disease. Am Rev Respir Dis 1991;143:1248-52. 
10 Baarends EM, Schols AMWJ, Pannemans DLE, Westerterp $\mathrm{KR}$, Wouters EFM. Total daily energy expenditure in clinically stable patients with severe COPD and agematched healthy subjects using the doubly labelled water technique. Am f Repir Crit Care Med 1997;155:549-54.

11 Hugli O, Schutz Y, Fitting JW. The daily energy expenditure in stable chronic obstructive pulmonary disease. $A m \mathcal{F}$ Respir Crit Care Med 1996;153:294-300.

12 Spicher V, Roulet M, Schutz Y. Assessment of total energy expenditure in free living patients with cystic fibrosis. $\mathcal{F}$ Pediatr 1991;118:865-72

13 Macallan DC, Noble C, Baldwin C, Jebb SA, Prentice AM, Coward WA, et al. Energy expenditure and wasting in
human immunodeficiency virus infection. $N$ Engl $7 \mathrm{Med}$ 1995;333:83-8.

14 American Thoracic Society. Standards for the diagnoses and care of patients with chronic obstructive pulmonary disease (COPD) and asthma. Am Rev Respir Dis 1987; 137:225-8

15 Quanjer Ph, ed. Standardized lung function testing. Eur Respir f 1993;6 (Suppl 16):5-40.

16 Schols AMWJ, Schoffelen PF, Ceulemans H, Wouters EFM, Saris WH. Measurement of REE in patients with COPD in a clinical setting. F Parenteral Enteral Nutr 1992:364-8.

17 Weir JB. New methods for calculating metabolic rate with special reference to protein metabolism. F Physiol 1949; 109:1-9.

18 Harris JA. Benedict FG. A biometric study of basal metabolism in man. Washington DC: Carnegie institute of Washington, in man. Washington DC: Carne
Publication No. 279, 1919.

19 Stichting Nederlands Voedingsstoffenbestand. Nevo tabel. 's Gravenhage: Voorlichtingsbureau voor de Voeding, 1986.

20 Schoeller DA, Ravussin E, Schutz Y, Acheson KJ, Baertschi P, Jequier E. Energy expenditure by double labeled water: validation in humans and proposed calculation. $A m \mathcal{F}$ Physiol 1986;250:R823-30.

21 Westerterp KR, Wouters L, Marken Lichtenbelt WD. The Maastricht protocol for the measurement of body composition and energy expenditure with labeled water Obesity Res 1995;3:49-57.

22 Schoeller DA. Isotope dilution methods. In: Bjöntrop P, Brodoff BN, eds. Obesity. Philadelphia: J.B. Lippincott, 1992: $80-8$.

23 Cunningham JJ. Body composition as a determinant of energy expenditure: a synthetic review and a proposed general prediction equation. Am f Clin Nutr 1991;54: $963-9$

24 Food and Agriculture Organization/World Health Organization/United Nations University. Energy and protein requirements. Technical Report Series No. 724. Geneva: WHO, 1985.

25 Carpenter WH, Poehlman ET, O`Connell M, Goran MJ. Influence of body composition and resting metabolic rate on variation in total energy expenditure: a meta-analysis. Am $\mathcal{f}$ Clin Nutr 1995;61:4-10.

26 Goldstein S, Askanazi J, Weissman C, Thomashow B, Kinney JM. Energy expenditure in patients with chronic obstructive pulmonary disease. Chest 1987;91:222-4.

27 Hugli O, Frascarolo P, Schutz Y, Leuenberger P, Fitting JW. Diet-induced thermogenesis in chronic obstructive pulmonary disease. Am Rev Respir Dis 1993;148:1479-83.

28 Green JH, Muers MF. Comparison between basal metabolic rate and diet-induced thermogenesis in different types of rate and diet-induced thermogenesis in different types of
chronic obstructive pulmonary disease. Clin Sci 1992;83: 109-16.

29 Meijer GA, Westerterp KR, Koper H, Ten Hoor F. Assessment of energy expenditure by recording heart rate and body acceleration. Med Sci Sports Exerc 1989;21: 343-7.

30 Schols AMWJ, Buurman WA, Staal-van den Brekel AJ, Dentener MA, Wouters EFM. Evidence for a relation between metabolic derangements and increased levels of inflammatory mediators in a subgroup of patients with chronic obstructive pulmonary disease. Thorax 1996;51 819-24.

31 Dash A, Agrawai A, Venkat N, Moxham J, Ponte J. Effect of oral theophylline on resting energy expenditure in norma volunteers. Thorax 1994;49:1116-20.

32 Amoroso P, Wilson SR, Moxham J, Ponte J. Acute effects of inhaled salbutamol on the metabolic rate of normal subjects. Thorax 1993;48:882-5.

33 Sridhar MK, Carter R, Lean MEJ, Banham SW. Resting energy expenditure and nutritional state of patients with increased oxygen cost of breathing due to emphysema scoliosis and thoracoplasty. Thorax 1994;49:781-5.

34 O'Donnell DE, Webb KA. Exertional breathlessness in patients with chronic airflow limitation. The role of hyperinflation. Am Rev Respir Dis 1993;148:1351-7.

35 Belman MJ, Botnick WC, Shin JW. Inhaled bronchodilators reduce dynamic hyperinflation during exercise in patients with chronic obstructive pulmonary disease. Am $\mathcal{F}$ Respir Crit Care Med 1996;153:967-75. 